\title{
Re-visioning Places of Public Gathering in the Contemporary Arab Urbanism
}

\author{
Mona Helmy \\ The British University in Egypt (BUE), Egypt \\ mona.helmy@bue.edu.eg
}

Over the past decades, contemporary urbanism in Arab cities has undergone a radical transformation under the influence of a variety of forces, such as globalization, with the influx of money, ideas, people, and development models. Consequently, development visions of cities in the Arab world have shifted from local to imported international models, generating new paradigms of Arab contemporary urbanism, which are strongly impacting on public places in particular. Imported international models in Arab Cities have varied between establishing new urban typologies resembling Western urban imagery and icons, gated communities, themed cities, gigantic commercial centres and shopping malls, among other models.

Places of public gathering in Arab cities are conceived as catalysts for change and as opportunities for domesticating and appropriating imported Western urban models. The multiplicity of opportunities for shaping, upgrading and rebuilding places of public gathering, from global paradigms to local realities, have stimulated many urban ambivalences and complexities, in which reconsidering places for public gathering nowadays implies a transdisciplinary understanding and a multifaceted perspective. The superimposing of changing concepts has critically transformed settings, structure, and functions of places for public gathering, while establishing the Arab urbanism as a brand new competitive urban system.

This themed issue of The Journal of Public Space brings together a variety of perspectives, approaches, reflections and ideas to provide a critical overview of contemporary places of public gathering in the Arab cities. Fourteen manuscripts, between papers and viewpoints were highly selected to cover a variety of sub-themes of places of public gathering in the Arab world, aiming at:

- $\quad$ Exploring new urban typologies of places of public gathering;

- $\quad$ Conceptualizing places of public gathering in various Arab cities under the forces of globalization trends;

- $\quad$ Examining the notion of the privatization of public places in Arab cities and its impact on people's social life;

- Exploring the impact of physical distancing and the relevant reclaiming of public places;

- Designing places to support social interaction and to generate social life; 
- $\quad$ Transforming shopping centres and malls into mixed-use community centres;

- Analysing how Eventifying places of public gathering in Arab cities is changing their setting, structure and function;

- Investigating various trends of Creative places of public gathering in Arab cities.

This themed edition commences with a critical editorial article by Prof. Nezar AlSayyad that debates the meanings and uses of urban space in the Arab City from a historical placemaking perspective in Arab Cities, in terms of realities, challenges, and prospects. In his article, AlSayyad claims that "there has never been a prototypical city in the Arab world, which is not considered a homogenous urban realm; including its different peoples, nations and political regimes have produced cities of different sizes, different densities, different sub-cultures and different levels of wealth". He argues that "people's interaction in space and the language of the street may provide more commonalities than differences" in the public gathering in the Arab context.

This themed issue is divided into four main sections. Three sections are classified as per the content of their included papers under three main categorizes that use Space, Society, and System as their dominant foundational and contextual domains. It also includes a Viewpoints section that showcases real practices in different contexts. Section one "Space" includes seven papers. It starts with a paper titled as "Urban Elements in the Saudi Arabian Najd Region and their Influence on Creating Threshold Spaces" by Mohammed Mashary Alnaim. The paper investigates how urban elements generate gathering spaces, and how these generated spaces are being transformed into threshold spaces within the built form. This done through a Space Syntax analysis technique, which examines a number of factors related to space, territory, society, culture, and environment.

Aseel Naamani, and Ruth Simpson are questioning if public spaces are venues for peacebuilding in Lebanon. In their paper with the same title, they investigate the role of civic movements in reclaiming public spaces in Beirut and Tripoli. They argued that “Urban spaces, including the country's two biggest cities - Beirut and Tripoli - have been largely privatized and have become the preserve of an elite few, and post-war development has been dogged by criticism of corruption and exclusivity". The paper states that reclaiming public spaces is central to reform and rebuilding relationships across divides after years of conflict as a cornerstone of peacebuilding efforts. In their paper "Investigating Users Changing Needs in Relation to nondesigned/Unplanned Public Spaces in Cairo" Joseph M. Namar, Mohamed A. Salheen, and Ayat Ismail critically review and find out theories and practices that provide solutions for dealing with non-designed open spaces development in terms of users changing needs and contributions. The paper studies the unplanned public spaces in Cairo in relation to the needs of the Cairines. The results of the paper include development considerations that need to be respected in Cairo public spaces with more concern for people's usage and interaction with the space.

The paper "The Redemptive Potential of the Street: A Multi-angular Analysis of Dubai's Pedestrian Infrastructure" by Lamia Abdelfattah, Filippo Bazzoni and Rawad Choubassi, offers several potentials for adapting Dubai's streetscape to make it more walkable year-round. 
It provides some key strategies to adaptively retrofit Dubai's streets in order to combat the current pandemic situation without risking the loss of active modes of travel, and to enhance walkability of the city on the long run.

In his paper "New Typologies of Contemporary Shopping Malls in Egypt", Karim Youssef traces new typologies in the design of mega shopping malls in Cairo as they integrate new public gathering spaces for leisure, recreation, and entertainment. Section one ends with a paper by Hellen Aziz, Salma Ellakany that discusses "The segregation in access to spaces for urban activities during COVID- 19 pandemic in relation to gated communities. Residential and beachfront gated communities in Egypt". The paper argues that the segregation in the rights of use of open urban spaces inside and outside gated communities, during the pandemic caused an increase of social interaction inside their boarders.

The second section of this themed issue focuses on "Society" as a base for creating new patterns of public gathering places in the Arab world. It begins with an interesting group research paper with the title of "COVID-19 Pandemic: between Public Space and Users' behaviours: Case studies from Egypt, Jordan, and Germany”. The paper is a joined effort of several researches, living in different cities/countries; to investigate and compare the relation between the governments' regulations regarding public space and citizens' behaviour in light of the COVID-19 pandemic in their counties. Authors Hassan Elmouelhi, Sara Nowar, Hellen Aziz, Nada Abdrabou, Ahmed Gaballah, and Tayseer Khairy, have recommended a collaborative framework in designing public spaces, that includes the local community in cooperation with urban planners and governments.

The paper "Fostering Interactions at Public Open Spaces: The Role of Physical interface in facilitating user interactions in the UAE" by Arushi Malhotra, and Ranjana Dobriyal aims at understanding the role of physical space in encouraging user interactions in the context of public open spaces. The research aims to signify the role of physical space interface for promoting interactions among its users in the UAE in a full equitable environment.

In his paper "Post-development practices of public space: between cohabitation and "domination" of new atmospheres" Abdellah Moussalih uses the case of Rabat dock, Rabat-Morocco. The paper investigates the social uses and practices of citizens to identify the evolution of the relationship between the transformation of spatial structures and the production of landscapes representative of the image of the urban area.

The third section of this themed issue includes a paper that focuses on the "Systems", which guides its research problem. In this section, Tarek Fouani questioned "What Happened to the Public Spaces of the Arab World? From Colonization to Revolution: The Case of Lebanon". The paper critically assesses the circumstances under which the European idea of public spaces was imported and implemented in the Arab context, in which spaces of public gathering in the Arab world lacked their essence.

The last section of this issue includes two viewpoints that showcase of real practices to enrich the theme of this issue on re-visioning places of public gathering in the contemporary Arab urbanism. The first viewpoint with the title "Public Spaces in the Arab Region" by Elaf Raslan and Lubna Shaheen from UN-Habitat, Regional office for Arab States, is stating that the Arab Region has been facing various challenges. While some countries are facing socio-economic issues, others have been civil strife and conflict. In both cases, public spaces play an important role in tackling these issues. The 
viewpoint discusses the term "private public spaces" as a notion that denies the right of citizens to use public spaces. Several case studies in the Arab world are presented to guide the needs for special programs to develop child friendly and women friendly public spaces. The viewpoint calls for a governance structures can still be further adopted to include stronger representation from the civil community and stronger ownership from the community.

Another viewpoint is contributed by May al-lbrashy. It represents part of the initiatives done by Megawra Built Environment Collective. In her viewpoint titled as "Heritage in the street: Megawra | BEC's Athar Lina Initiative in Historic Cairo" May al-lbrashy narrates how urban issues in al-khalifa was tackled. Using a comprehensive participatory approach on all levels, a series of participatory research and design meetings to study the relationship between the heritage of the street and the community. This was done through not only physical interventions in public spaces, but also through people's activities that celebrate al-Khalifa area.

In conclusion, this themed issue did not intend to give ready recipes to create or to revisioning places of public gathering in the contemporary Arab urbanism, rather it attempts to drop stones into still water; to create waves of ideas, initiatives, and actions. Through a journey of very rich and diverse problems, analysis, discussions and recommendations presented in the peer-reviewed articles, this issue sheds light on the importance of contemporizing our conventional ways of gathering in public places. It proofs that there is a need for fresh innovative perspectives of planning and designing public places for social gathering in the Arab world, not only to solve the possible emerged malfunction of some social gathering places, but to re-vision them as a whole experience, where socio-cultural aspects are celebrated.

And finally, I have the honour as the main editor to present this special issue as a humble contribution to such hopeful re-visioning.

To cite this article:

Helmy, M. (202I) Re-visioning Places of Public Gathering in the Contemporary Arab Urbanism, The Journal of Public Space, 6(I), I-4, DOI I0.3289I/jps.v6i I.I456 